\title{
Analysis and Comparison between Reference Harmonic Current Detection Strategies Adopted in (APF) Control Methods
}

\author{
Adam Misbawu ${ }^{1, a,}$, Chen Yuepeng ${ }^{1, b}$ and Deng Xiangtian ${ }^{1, c}$ \\ School of Automation, Wuhan University of Technology, Wuhan, China \\ *2944494252@qq.com
}

Keywords: Active power filters, harmonic currents, $p-q$ theory and $i_{p}-i_{q}$ theory.

\begin{abstract}
The fundamental purpose of this paper is to present the difference between strategies for extraction of reference compensation currents for harmonic mitigation in a non-linear load. APFs are used to compensate for the harmonic current generated by nonlinear loads. These harmonic currents are produced due to intensive use of power electronic loads such as rectifiers; variable speed drives (VSD), uninterrupted power supply (UPS) etc. The emphasis is given to the method of determining the reference compensation currents. The $p-q$ theory and the $i_{p}-i_{q}$ theory strategies were analyzed in this paper. The adopted compensation current directions indicate whether the harmonic compensation current is supplied or drawn from the source current. Both strategies can be used for the compensation of harmonic current in non-linear loads, in a micro-grid etc., nevertheless their methods of reference harmonic current detection are different.
\end{abstract}

\section{Introduction}

Among the different new technical options available to improve power quality, active power filters [1-3] have proved to be an important and flexible alternative to compensate for current and voltage disturbances in power distribution systems. The idea of active power filters is relatively old, but their practical development was made possible with the progress of the new improvement in power electronics. The function of APF's varies depending on the applications. They are used in low to medium distribution levels or for reactive power and/or voltage control at high-voltage distribution levels to generally control current harmonics in the supply network.

Too high harmonic distortion results in reduction of productivity, reduction in components life span and can even damage equipment. Unbalanced loads such as personal computers (PC's) causes' excessive current in the neutral, which may give rise to impermissible voltage levels between neutral and earth and may results in physical danger and equipment malfunctioning [4].

The intensive use of power electronic loads such as rectifiers, variable speed drives (VSD), uninterrupted power supply (UPS) etc. [5-7].

Figure 1 shows a Block diagram of a Shunt APF topology. The topology consists of the voltage 
source supplying the source current. The non-linear load draws the fundamental current $i_{L k}$ and the harmonic current $i_{h k}$ from the source. Active power filter compensates for the load harmonic current, so that the source can only supply the fundamental current $i_{S k}$. (k=a, b and c phases).

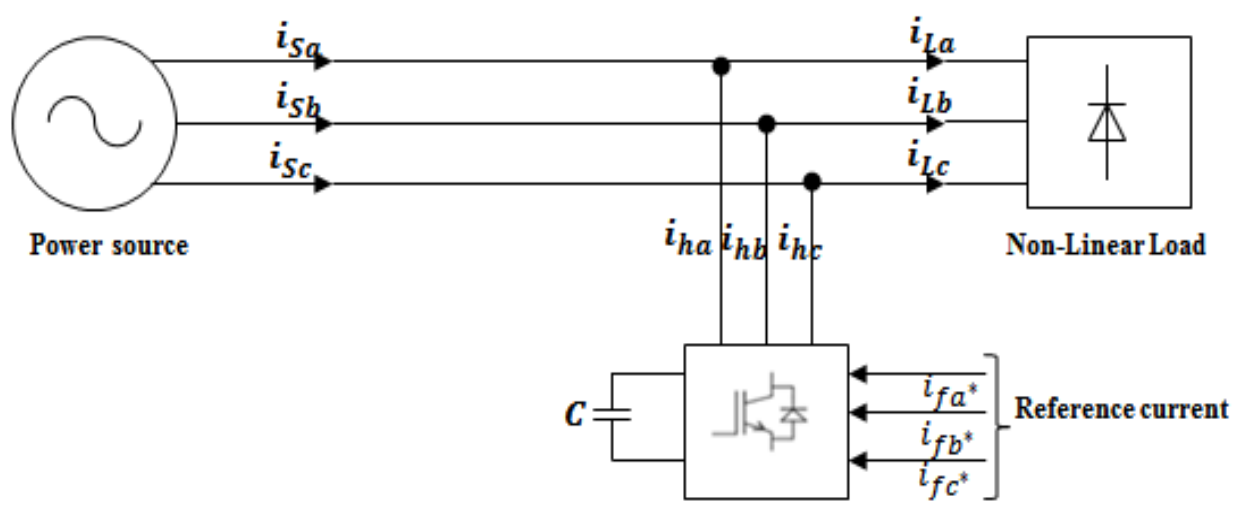

Figure 1 Block diagram of a shunt APF.

In this paper, a comparison between two types of shunt active power filters control strategies, Instantaneous real and reactive power theory ( $p-q$ theory), and $i_{p}-i_{q}$ theory methods are presented for the extraction of the reference current connected to three-phase three wire source that supplies a non-linear load. Based on these control strategies, a simulation will be used to prove the viability of the strategies in terms of determining the reference current.

The paper is organized as follows: Section II describes the $p-q$ active power filter control strategy and section III the $i_{p}-i_{q}$ system description and modeling is shown. Simulation results are presented and analyzed in section IV. Section V is the conclusion of the paper.

\section{Instantaneous Active and Reactive Power Theory ( $P-Q$ Theory)}

This method is also known as the p-q theory, method [12-14]. This theory was first introduced by Akagi in 1984 [12]. The $p-q$ theory is based on a set of instantaneous power definition in the time domain. This control method is used to generate reference source current [15-16]. The voltage or current waveforms have no restrictions and it can be suitable to three-phase system with or without a neutral wire for three-phase generic voltage and current waveforms. The $p-q$ theory uses the $\alpha \beta o$ transformation, also known as the Clarke transformation [17-18], which consists of a real matrix that transforms three-phase voltages and current into the $\alpha \beta o$ stationary reference system using the following equations:

$$
\left[\begin{array}{l}
v_{o} \\
v_{\alpha} \\
v_{\beta}
\end{array}\right]=\sqrt{\frac{2}{3}}\left[\begin{array}{ccc}
\frac{1}{\sqrt{2}} & \frac{1}{\sqrt{2}} & \frac{1}{\sqrt{2}} \\
1 & -\frac{1}{2} & -\frac{1}{2} \\
0 & \frac{\sqrt{3}}{2} & -\frac{\sqrt{3}}{2}
\end{array}\right]\left[\begin{array}{l}
v_{a} \\
v_{b} \\
v_{c}
\end{array}\right] \quad \text { and }\left[\begin{array}{l}
i_{o} \\
i_{\alpha} \\
i_{\beta}
\end{array}\right]=\sqrt{\frac{2}{3}}\left[\begin{array}{ccc}
\frac{1}{\sqrt{2}} & \frac{1}{\sqrt{2}} & \frac{1}{\sqrt{2}} \\
1 & -\frac{1}{2} & -\frac{1}{2} \\
0 & \frac{\sqrt{3}}{2} & -\frac{\sqrt{3}}{2}
\end{array}\right]\left[\begin{array}{l}
i_{a} \\
i_{b} \\
i_{c}
\end{array}\right]
$$


The active and reactive power in this method consists of constant (DC) component and oscillating (AC) component with the assumption that the system is a symmetric three-phase or there is no neutral point [19].

$$
\left[\begin{array}{l}
p \\
q
\end{array}\right]=\left[\begin{array}{cc}
v_{\alpha} & v_{\beta} \\
v_{\beta} & -v_{\alpha}
\end{array}\right]\left[\begin{array}{l}
i_{\alpha} \\
i_{\beta}
\end{array}\right]
$$

Equation (2) can be decomposed into two AC and DC parts as;

$$
\begin{aligned}
& p=\bar{p}+\tilde{p} \\
& q=\bar{q}+\tilde{q}
\end{aligned}
$$

Where:

$\bar{p}$ : is the DC component of the instantaneous power $p$, and is related to the fundamental active current,

$\tilde{p}$ : is the AC component of the instantaneous power $p$, it does not have average value, and is related to harmonic current caused by the AC component of the instantaneous real power

$\bar{q}$ : is the DC component of the instantaneous imaginary power $q$, and is related to the reactive power generated by the fundamental components of the voltages and current.

$\tilde{q}$ : is the AC component of the instantaneous imaginary power $q$, and is related to the harmonic current generated by the AC components of instantaneous reactive power.

The active and reactive powers are extracted using low-pass filters (LPF). The oscillating components of the powers are also obtained by;

$$
\begin{aligned}
& \tilde{p}=p-\bar{p} \\
& \tilde{q}=q-\bar{q}
\end{aligned}
$$

The value of the average real power $\left(\bar{p}_{\text {loss }}\right)$ represented in figure 2 is added to the oscillating active power $(\tilde{p})$. Using the reverse Clarke transformation to calculate the reference values for the active filters given as follows:

$$
\left[\begin{array}{c}
i_{\alpha^{*}} \\
i_{\beta^{*}}
\end{array}\right]=\frac{1}{v_{\alpha}^{2}+v_{\beta}^{2}}\left[\begin{array}{cc}
v_{\alpha} & v_{\beta} \\
v_{\beta} & -v_{\alpha}
\end{array}\right]\left[\begin{array}{l}
p^{*} \\
q^{*}
\end{array}\right]
$$

Where;

$$
\begin{aligned}
p^{*} & =\tilde{p}+\bar{p}_{\text {loss }} \\
q^{*} & =\tilde{q}
\end{aligned}
$$

The ( $a b c$ ) reference values for the active power filter is given by; 


$$
\left[\begin{array}{l}
i_{a f^{*}} \\
i_{b f^{*}} \\
i_{c f^{*}}
\end{array}\right]=\sqrt{\frac{2}{3}}\left[\begin{array}{cc}
1 & 0 \\
-\frac{1}{2} & \frac{\sqrt{3}}{2} \\
-\frac{1}{2} & -\frac{\sqrt{3}}{2}
\end{array}\right]\left[\begin{array}{l}
i_{\alpha^{*}} \\
i_{\beta^{*}}
\end{array}\right]
$$

Figure 2 shows the block diagram of the instantaneous Active and Reactive Power Theory ( $P-Q$ theory).

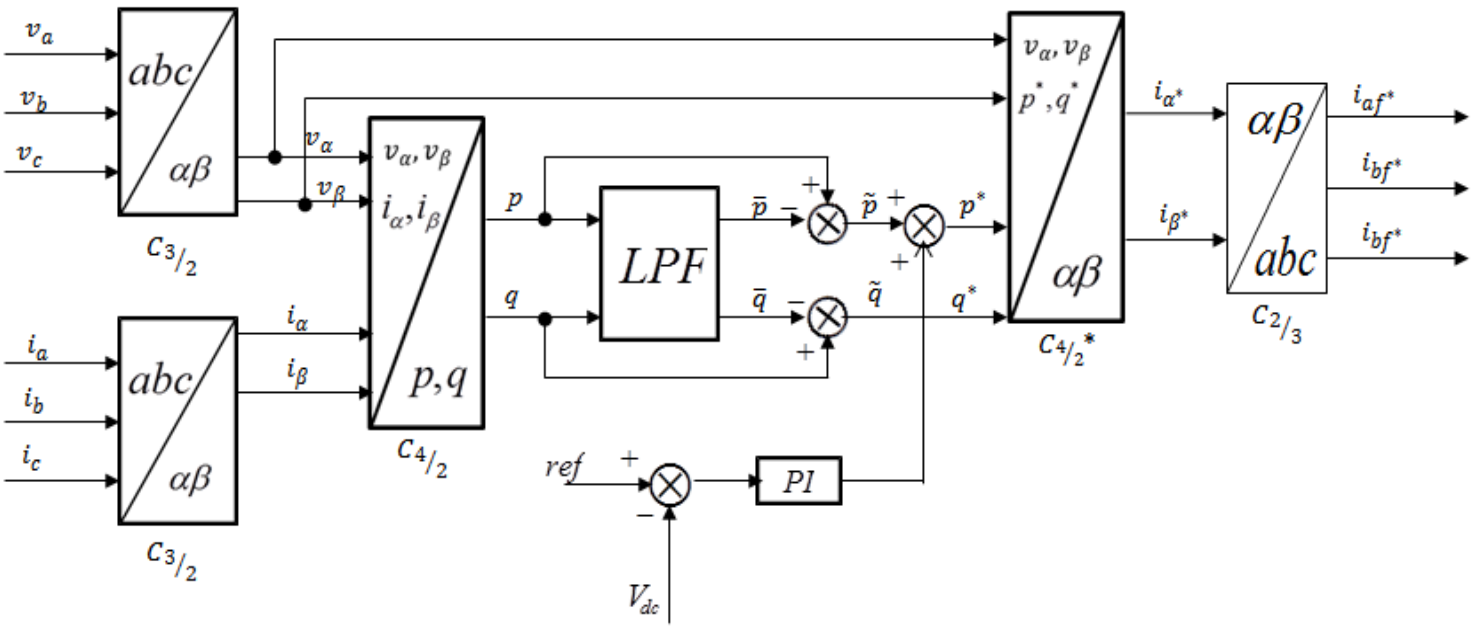

Figure 2 Block diagram of instantaneous active and reactive power theory for reference current detection.

Figure 3 shows a block diagram of shunt active filter using the principles of $p-q$ theory to determine the reference current. The adopted current directions in figure 3 indicate that the supply current is given by the sum of the load and the compensation current. This can be obtained by negating the $p^{*}$ and $q^{*}$ to calculate for $i_{\alpha^{*}}$ and $i_{\beta^{*}}$. The three-phase instantaneous values of the compensating reference currents $i_{a f^{*}}, i_{b f^{*}}$ and $i_{c f^{*}}$ can also be obtained using the inverse Clark transform.

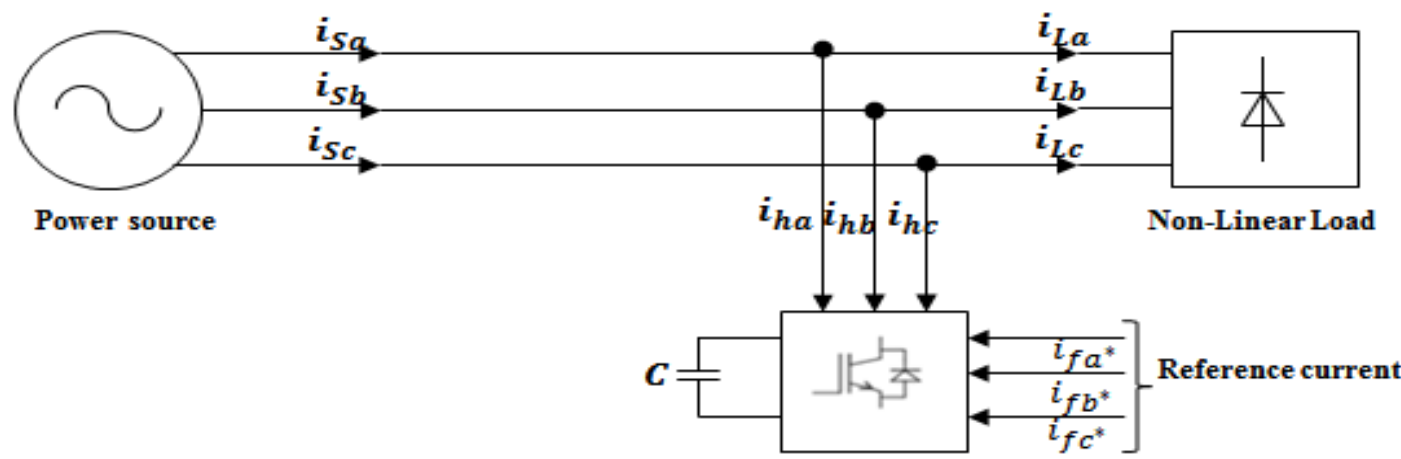

Figure 3 Block diagram of $p-q$ principles. 


\section{The $\left({ }^{i_{p}}-i_{q}\right)$ Active Power Fillter Theory}

The control circuit of the APF is shown in the figure 4. Based on the theory of instantaneous power, the current detection method is commonly used in detecting the power network harmonics and reactive components.

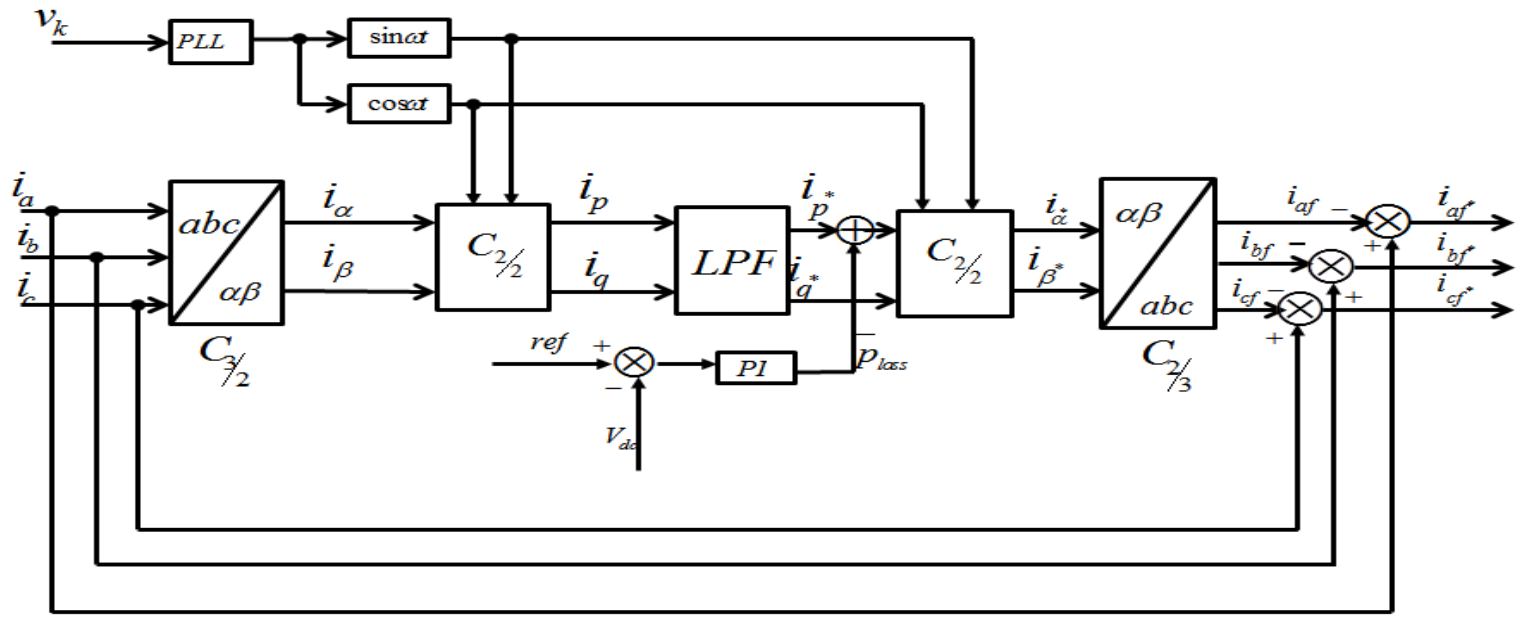

Figure 4 Block diagram for the APF reference current detection.

In figure 4, phase locked loop (PLL) is a circuit building block particularly noted for its flexibility. The basic operating concept of the PLL is relatively simple, even though the mathematical analysis and various elements of its procedure can be complicated. It synchronizes the voltage control oscillator (VCO) with reference frequency through a feedback to generate a stable higher output frequency from a fixed low frequency signal. VCO generates oscillating waveforms at varying frequency. Here, the PLL with sine and cosine wave generating circuit is used to generate sine and cosine signals ( $\sin \omega t$ and $\cos \omega t$ ) which must be in phase with the compensating current.

The basic operating principles of the control circuit of the APF shown in fig 1 are as follows; according to the instantaneous power theory [17-18]. The Clark transformation maps the threephase instantaneous line currents in, the $\mathrm{a}, \mathrm{b}$, and c phase $i_{a}, i_{b}$, and $i_{c}$ into the instantaneous current on the $\alpha \beta-$ axes $i_{\alpha}$ and $i_{\beta}$ given by;

$$
\left[\frac{i_{\alpha}}{i_{\beta}}\right]=C_{3 / 2}\left[\begin{array}{l}
i_{a} \\
i_{b} \\
i_{c}
\end{array}\right]
$$

Where;

$$
C_{3 / 2}=\sqrt{\frac{2}{3}}\left[\begin{array}{ccc}
1 & -0.5 & -0.5 \\
0 & \frac{\sqrt{3}}{2} & -\frac{\sqrt{3}}{2}
\end{array}\right]
$$

The $p-q$ transformation is used to obtain instantaneous active and reactive currents $i_{p}$ and $i_{q}$ respectively, given by; 


$$
\left[\begin{array}{l}
i_{p} \\
i_{q}
\end{array}\right]=C_{2 / 2}\left[\begin{array}{l}
i_{\alpha} \\
i_{\beta}
\end{array}\right]
$$

Where;

$$
C_{2 / 2}=\left[\begin{array}{ll}
\sin \omega t & -\cos \omega t \\
-\cos \omega t & -\sin \omega t
\end{array}\right]
$$

$i_{p}$ and $i_{q}$, then passed through a low pass filter to attain $i_{p^{*}}$ and $i_{q^{*}}$ which are the instantaneous active and reactive DC components of the currents. The Clark transformation is also used to generate the DC components of the instantaneous currents on $\alpha \beta$-axes $i_{\alpha^{*}}$ and $i_{\beta^{*}}$ given by:

$$
\left[\begin{array}{l}
i_{\alpha^{*}} \\
i_{\beta^{*}}
\end{array}\right]=C_{2 / 2}\left[\begin{array}{l}
i_{p^{*}} \\
i_{q^{*}}
\end{array}\right]
$$

Then, the inverse Clark transformation from $\alpha \beta$-axes to $a, b$, and $c$ is applied to determine the instantaneous values of the three-phase compensating current referred to as $i_{f a} i_{f b}$ and $i_{f c}$ respectively. The fundamental components $i_{f a} i_{f b}$ and $i_{f c}$ can be generated as follows;

$$
\left[\begin{array}{l}
i_{f a} \\
i_{f b} \\
i_{f c}
\end{array}\right]=C_{2} / 3\left[\begin{array}{l}
i_{\alpha^{*}} \\
i_{\beta^{*}}
\end{array}\right]
$$

Where;

$$
C_{2 / 3}=C_{3 / 2}=\sqrt{\frac{2}{3}}\left[\begin{array}{cc}
1 & 0 \\
-0.5 & \frac{\sqrt{3}}{2} \\
-0.5 & -\frac{\sqrt{3}}{2}
\end{array}\right]
$$

Figure 5 shows a block diagram of shunt active filter using the principles of $i_{p}-i_{q}$ theory to determine the reference current. The adopted current directions in fig 5 indicate that the supply current plus the compensation current is equal to the load. The active filter supplies the harmonic current to compensate for the load harmonic current, so that the source can only supply the fundamental currents. The three-phase instantaneous values of the compensating reference currents, $i_{a f^{*}}, i_{b f^{*}}$ and $i_{c f^{*}}$ can also be obtained by subtracting the reference current from the load current. 


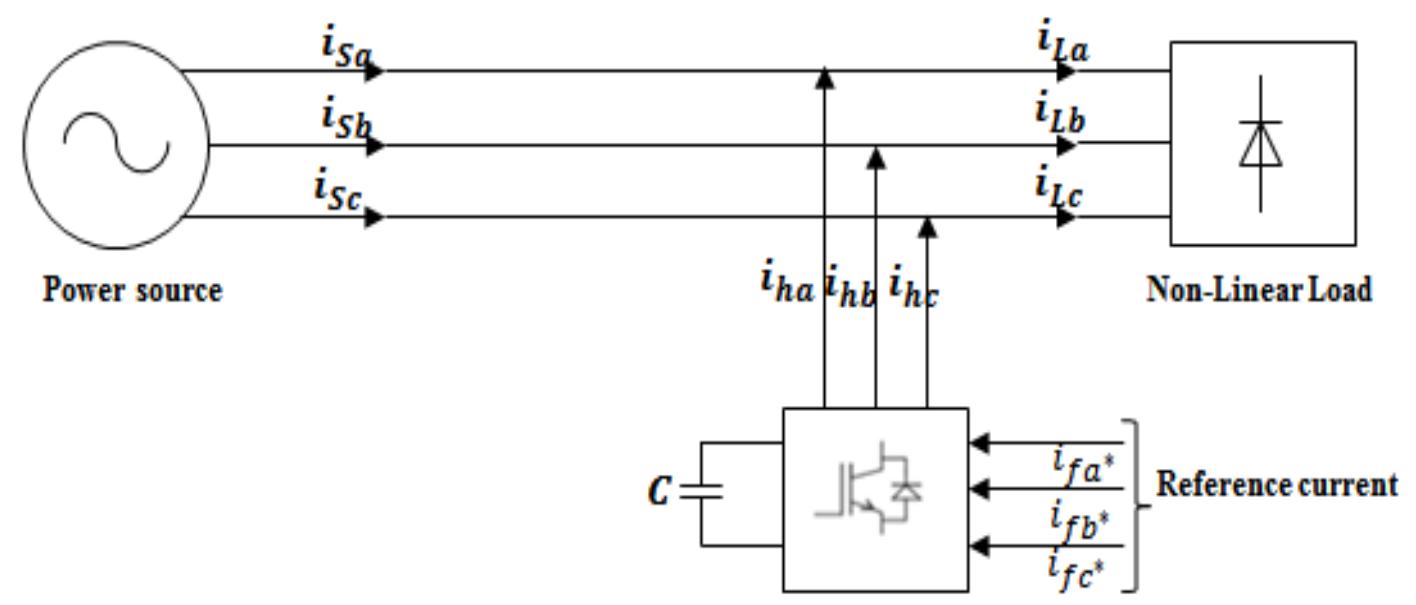

Figure 5 Block diagram of $i_{p}-i_{q}$ principle.

\section{Simulation Results}

\section{1. $P-Q$ Theory}

Figures 6-7 shows the various possible reference waveforms, obtained from the $p-q$ principles of figure 2 and with the control technique of figure 3. A three phase diode rectifier was considered as the non-linear load in these cases. Neutral current was ignored. Figures 6 show the $\alpha \beta$ components from the load current that was used to generate the reference currents. Figure 7 (a) shows only aphase of the compensating reference current and fig 7 (b) shows the compensation of the load harmonic current. It can be seen that the harmonic current has been compensated by the generated harmonic reference current.

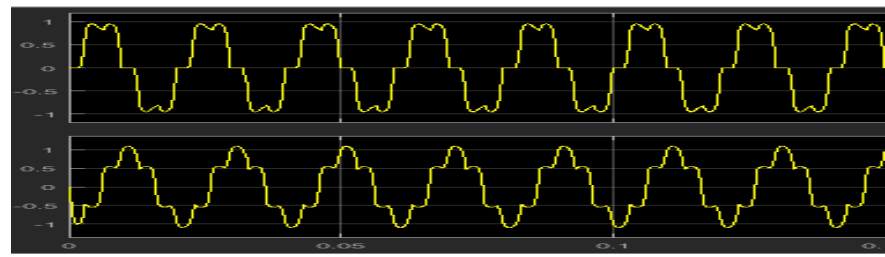

(a)

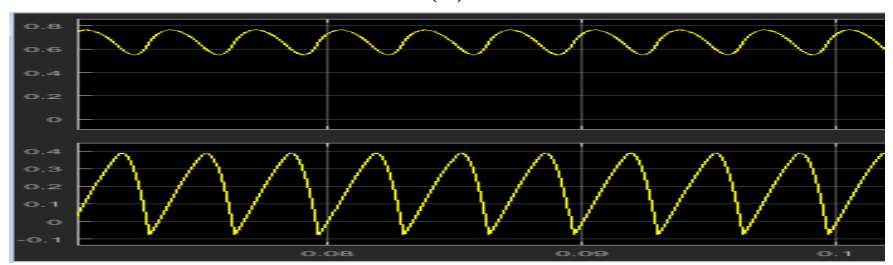

(b)

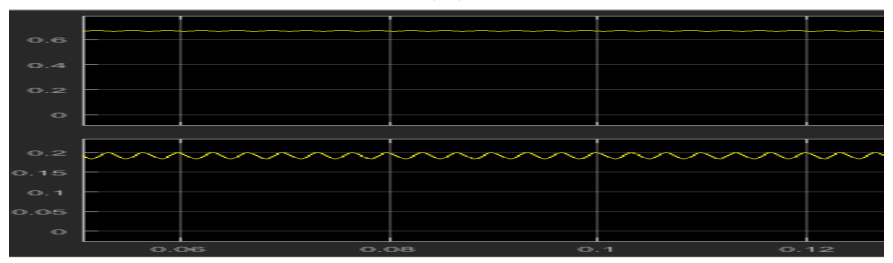

(c) 


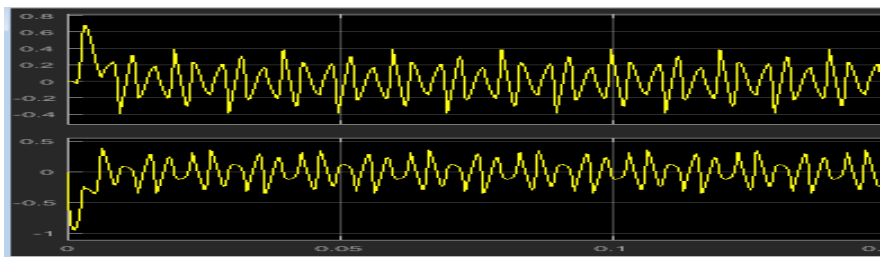

(d)

Figure 6 Compensating waveforms. (a) $\alpha \beta$ Components of the load current. (b) $p-q$ Waveforms. (c) $p-q$ Output waveforms of the LPF. (d) $\alpha \beta$ Compensating reference current.

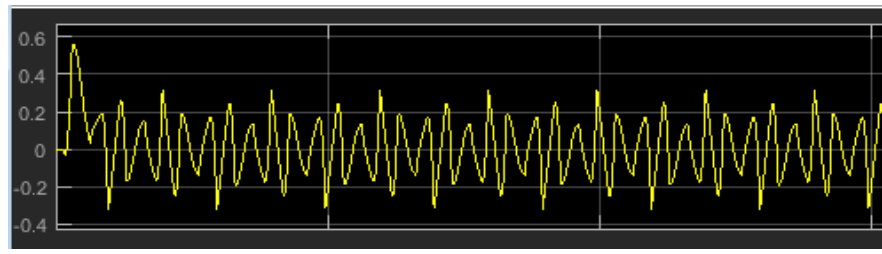

(a)

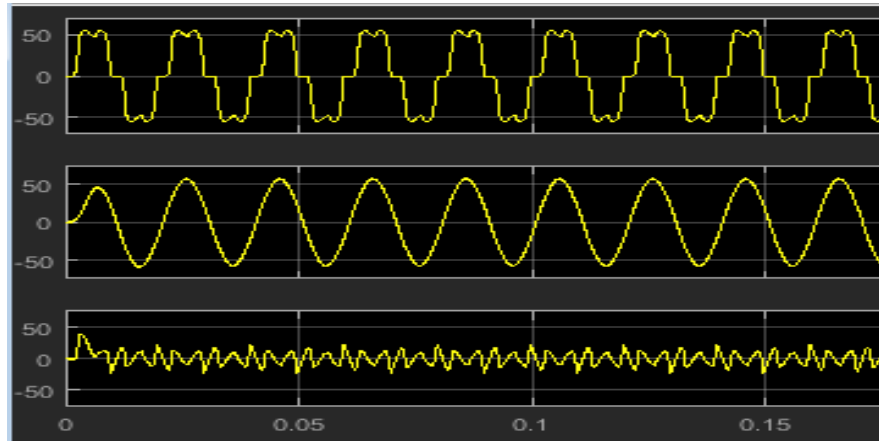

(b)

Figure 7(a) Phase-a of the reference compensation current (b) Harmonic compensation of the load current.

\section{2. $I_{p}-I_{q}$ Theory}

Figures 8-9 also shows the various possible reference waveforms, obtained from the $i_{p}-i_{q}$ principles of figure 4 and with the control technique of figure 5. A three phase diode rectifier was considered as the non-linear load in these cases. Neutral current was ignored. Figures 8 show the $\alpha \beta$ components from the load current that was used to generate the reference currents. Figure 9 (a) shows only a-phase of the compensating reference current and fig 9 (b) shows the compensation of the load harmonic current. It can be seen that the harmonic current has been compensated by the generated harmonic reference current

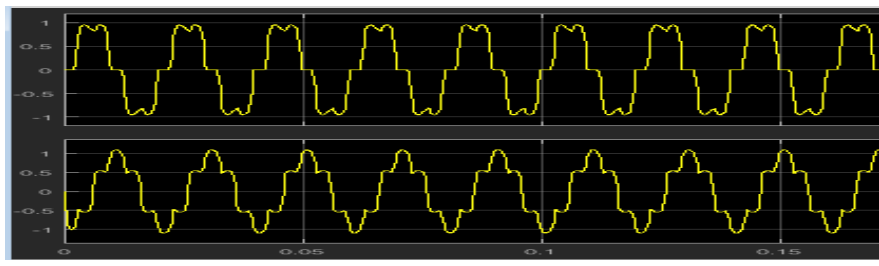

(a) 


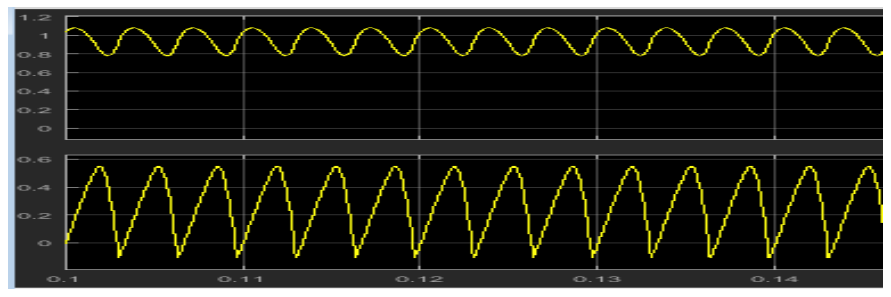

(b)

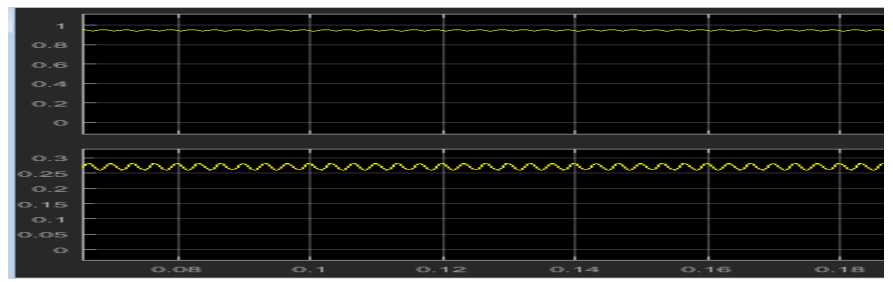

(c)

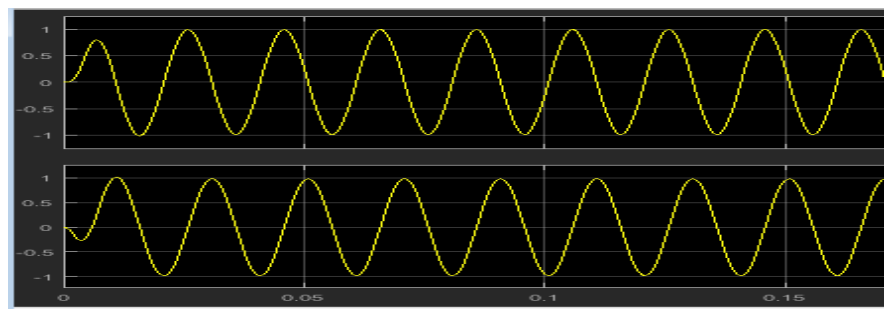

(d)

Figure 8 Compensating waveforms. (a) $\alpha \beta$ Components of the load current. (b) $i_{p}-i_{q}$ Waveforms. (c) $i_{p}-i_{q}$ Output waveforms of the LPF. (d) $\alpha \beta$ Sinusoidal current extracted from the load current.

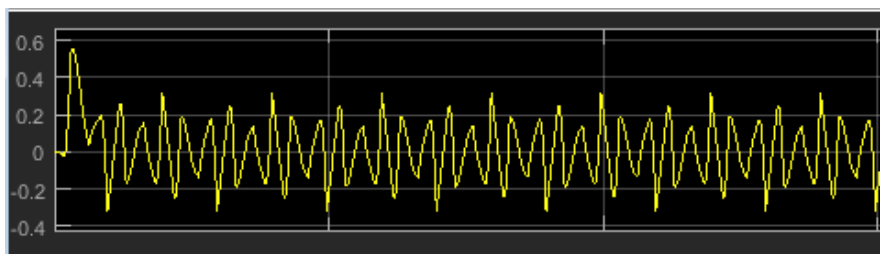

(a)

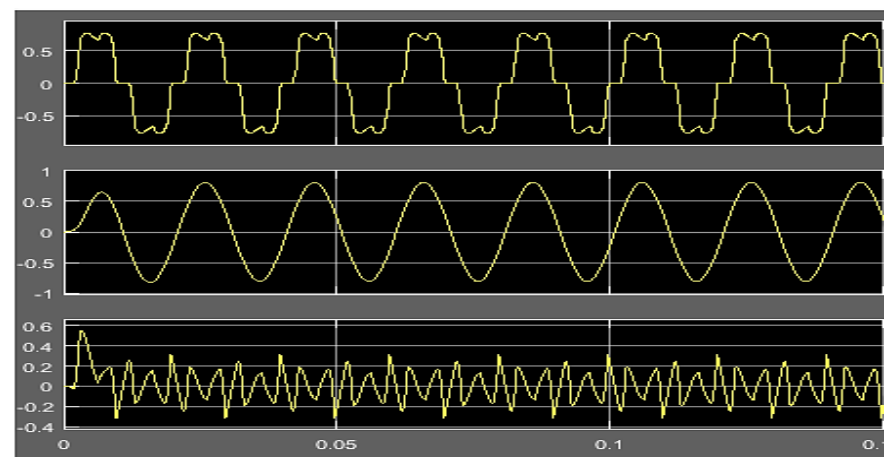

(b)

Figure 9(a) Phase-a of the reference compensation current (b) Harmonic compensation of the load current for phase a. 


\section{Conclusion}

In this paper, the active power filter control strategies base on $p-q$ theory and $i_{p}-i_{q}$ theory was compared on the basis of harmonic current detection and compensation. The paper presents a simulation results that show that the $p-q$ strategy is used to generate compensation current that is equal but opposite to the harmonic current. Therefore, the compensating current is subtracted from the current source.

But on the contrary, the $i_{p}-i_{q}$ strategy generates compensation current by subtracting the reference compensation current from the load current. Hence, both theories can be used to compensate for the harmonic current in non-linear loads and also in a micro-grid, even though their methods of compensation are different.

\section{Acknowledgment}

This work was supported by Natural Science Foundation of China (NSFC) under Grant (61374151)

\section{References}

[1] IEEE Working Group on Power System Harmonics, (1983), “Power system harmonics: An overview,” IEEE Trans. Power App. Syst., pp. 2455-2460.

[2] Shuter T. C., Vollkommer, H. T., Jr., and Kirkpatrick, J. L. (1989), "Survey of harmonic levels on the American electric power distribution system,” IEEE Trans. Power Delivery, vol. 4, pp. 2204-2213.

[3] Subjak Jr, J. S. and Mcquilkin, J. S. (1990), "Harmonics-causes, effects, measurements, analysis: An update,” IEEE Trans. Ind. Applicat., vol. 26, pp. 1034-1042.

[4] Martzloff, F. and Gruzs, T. (1988), "Power quality site surveys: facts, fiction and fallacies,” IEEE Transactions on Industry Applications, 24 (6), pp. 1005-1018.

[5] Peng, F.Z., Akagi, H. and Nabae, A. (1993), "Compensation characteristics of the combined system of shunt passive and series active filters.” IEEE Trans. Indus. Appl., pp. 144-152.

[6] Salmerón, P., Litrán, S.P. (2010), “A control strategy for hybrid power filters to compensate four-wires threephase systems.” IEEE Trans. Power Electron. 25, pp. 1923-1931.

[3] Salmerón, P., Litrán, S.P. (2010), "Improvement of the electric power quality using series active and shunt passive filters.” IEEE Trans. Power Del. 25, pp. 1058-1067.

[8] Cheng, P. T., Bhattacharya, S. and Divan, D. M. (1996), "Hybrid solutions for improving passive filter performance in high power applications,” in Proc. IEEE APEC’96, pp. 911-917.

[9] Soares, V., Verdelho, P. and Marques, G. D. (2000), “An instantaneous active and reactive current component method for active filters,” IEEE Trans. Power Electron., vol. 15, pp. 660-669.

[10] María, I.M. M., Enrique, R. C., and Fermín, B. G. (2007),"Comparison of Control Strategies for Shunt Active Power Filters in Three-Phase Four-Wire Systems," IEEE Transactions On Power Electronics, Vol. 22, pp229-236.

[11] Pittorino, L.A., Horn, A. and Enslin, J.H., (1996), "Power theory evaluation for the control of an active power filter," in Proceedings of the IEEE 4th AFRICON, vol. 2, pp. 676-681.

[12] Akagi, H., Tsukamoto,Y. and Nabae, A. (1990), "Analysis, design of an active power filter using quad-series voltage source PWM converters,” IEEE Trans. Ind. Applicat., vol. 26, , pp. 93-98.

[13] Rossetto, L. and Tenti, P. (1990), "Using AC-fed PWM converters as instantaneous reactive power compensators,” in Proc. IEEE PESC’90, pp. 855-861.

[14] Peng, F.Z., Akagi, H. and Nabae, A. (1990), “A new approach to harmonic compensation in power systems-A combined system of shunt passive, series active filters,” IEEE Trans. Ind. Applicat., vol. 26, pp. 983-990.

[15] Zahira, F. a.peer fathima. (2012) "A technical survey on control strategies of active filter for harmonic suppression”, ICCTS.

[16] Donghua, C., Shaojun x. (2010) "Review of the control strategies applied to active power filters" IEEE conference,.

[17] Clarke, E. (1943) "Circuit Analysis of A-C Power Systems, Vol. I-Symmetrical and Related Components,” Wiley.

[18] McCulloch, W. and Walter P. (1943), "A Logical Calculus of Ideas Immanent in Nervous Activity". Bulletin of Mathematical Biophysics 5 (4): pp.115- 133. 
[19] JOU, H.L. (1995), 'Performance comparison of the three phase active power filter algorithms', IEE Proc. Gener. Transmi. Distrib., 142, (6), pp. 646-652. 